\title{
TOPIC CHOICE FOR A STEM LESSON WITH LOCAL PRACTICE CONTEXT
}

\author{
Chung Kim Thi Nguyen ${ }^{1,+}$, \\ Thuy Phuong Thi Huynh', \\ Huong Xuan Dao', \\ Lai Bich Thi Dinh', \\ Hao Thi Mai ${ }^{1}$, \\ Diep Hong Ngo ${ }^{1}$
}

\section{Article History}

Received: 19 September 2020

Accepted: 15 November 2020

Published: 30 December 2020

\section{Keywords}

STEM education, local issues, practical, motivation, STEM lession

\author{
${ }^{1}$ Thu Dau Mot University, Vietnam; \\ ${ }^{2}$ Tan Phuoc Khanh High School, Binh Duong province, Vietnam \\ ${ }^{+}$Corresponding author • Email: chungntk@tdmu.edu.vn
}

\begin{abstract}
One of the main features of STEM education is to be oriented towards practical activities and knowledge application to solve real-life problems. However, in the first step of deployment, teachers often use copied problem contexts from abroad. There are many difficulties in approaching, creating excitement and motivation for students when it is not close to their real life. The more relevant the topic to the real local context is, the more important it is to motivate students to participate and at the same time make it easy for teachers to find topics for the STEM educational model. In this study, when choosing a topic associated with a real local context, both teachers and students easily reach and achieve goals with the STEM educational model.
\end{abstract}

\section{INTRODUCTION}

In the overall general education program draft, STEM education has been focused through the following manifestations: New general education program has full STEM subjects such as Mathematics; Natural Sciences; Technology; Information Technology. The position and role of informatics education and technology education in the new general education program have been significantly enhanced. This not only shows the ideology of STEM education but also the timely adjustment of general education before the 4.0 industrial revolution.

Expect STEM topics in the integrated subject program at the stage of basic education such as Nature and Society, Science, Informatics and Technology (in primary schools), Natural Science (in secondary schools); Orientation for innovating the educational method stated in the general education program by STEM education at the level of integrated teaching by interdisciplinary topics and applying interdisciplinary knowledge to solve practical problems (Ministry of Education and Training, 2019b).

However, while including the education ministry's training reference, the selected topics are compiled from abroad without the context of local practice (Ministry of Education and Training, 2019a). It has lacked of instruction on how to create situations and contexts associated with local reality. This will create a compulsion for both teachers and learners.

In this article, the authors build STEM topics that are relevant to the local real-world context when conducting STEM lessons.

\section{LITERATURE REVIEW}

STEM education is an interdisciplinary approach to the learning process in which disciplined academic concepts are integrated with real-world lessons, where students apply the knowledge in science, technology, engineering and maths into specific contexts (Tsupros et al., 2009).

Le Xuan Quang (2017) stated: "STEM education is a teaching perspective with an interdisciplinary approach from two of the areas of Science, Technology, Engineering and Math. In STEM education, learning content is associated with real practice, teaching method according to action-oriented teaching point of view.

Nowadays, STEM education is interested in research by many organizations and educators. Developing STEM education in the context of the 4th industrial revolution is not only a trend of the time but also a strategy of many countries because it will create a competitive advantage when implementing policies, training human resources and making available resources for the policy implementation (Nguyen Thanh Hai, 2019).

Unlike developed countries such as the U.S.A., STEM education imported into Vietnam was not derived from educational science research or macro policies on human resources, but from robotics competitions for high school 
students, which are deployed by technology companies in Vietnam together with foreign organizations. For example, the Robotics contest of DTT Eduspec company has been held since 2012 (STEM, 2012) along with the official seminars organized by DTT Eduspec company with the orientation of STEM education, focusing on new subjects like robotics or data science. Since then, STEM education has started to spread with many different forms, many different ways of implementation, and many different supporting organizations. The private education system in Vietnam has been very quick to bring STEM education in teaching, which is mainly robotics activities, to teach at schools in some big cities such as Hanoi, Ho Chi Minh city, Da Nang in the form of socialization (Nguyen Chi Thanh \& Dang Van Son, 2019).

Because the approach to STEM education in Vietnam is compiled from different sources in the world, topic contexts are often translated and copied from abroad where very few contexts are associated with the actual local contexts.

The one-hour STEM teaching criterion emphasizes that the topic of the STEM lesson focuses on problems of practice.

In STEM lessons, students are put into real social, economic, and environmental problems and asked to find solutions.

Thus, STEM lessons must focus on solving practical problems. Why is choice a matter of fact? First, it motivates students to see the meaning of their work. Second, it allows students to experience not under ideal conditions (eliminating the confounding elements of reality, which is not possible with today's exercises).

\section{RESEARCH METHODS AND RESULTS}

\subsection{Research methods}

Theoretical and experimental analysis method: This study builds on the theories of STEM lesson building processes and conducts experiments to compare the application process in the context of the lessons associated with local reality and a borrowed context.

In this study, we build the topic STEM education for Physics teaching. The model was tested at Block 8 of Thoi Hoa, Ben Cat secondary school, at Block 10 of Tan Phuoc Khanh Binh Duong High School, performed at the STEM / STEAM experience festival held by Binh Duong province.

\subsection{The process of building STEM lessons}

STEM lessons are built with the following steps:

1. Determining knowledge in the curriculum and other subjects to integrate: Archimedes thrust, soundproof materials, simple mechanical machines...

2. Looking for practical applications of this knowledge. For example, Archimedes thrust - manufacturing boats, submarines, canoes, etc., soundproofing materials - soundproof houses.

3. Building stories associated with the real local context, hot news.

4. Problem Identification: After choosing the topic of the lesson, it is necessary to identify the problem for students to solve. At this step, attention should be paid to the use of media and materials. The problem of solving is that it is reused the old practice tools as: technical assemblies, generators, mirrors, etc., and waste materials such as paper boxes, plastic bottles, ice cream sticks, etc.

5. Problem-solving requires linking with future careers: Design problem-solving lessons that relate to future careers.

6. Building evaluation criteria: It is necessary to clearly define the evaluation criteria, to help students orient in searching for building knowledge and solutions. At the same time, it helps teachers evaluate and control goals.

7. Designing the teaching process: To design activities for the teaching process, we use the reverse classroom model and the extended 5E model. Here we use the reverse classroom model to help students actively learn outside of school hours while reducing the amount of time spent studying in the classroom to ensure that the program duration is not increased. In our classroom space, we flexibly use laboratories, classrooms, and school grounds to match topic content.

\subsection{Contexts are made concrete for the lesson}

\subsubsection{Local context of flood situation}

In the lesson of Archimedes thrust, we choose the scene that occurs in Binh Duong, when heavy rain lasts, many roads are submerged in water, traffic is paralyzed for many hours (Figure 1a). In this context, students had 
experienced which means they saw. So we chose as the setting for the theme. It is easy to elicit students to remember context, and inadequacies that mean "problem" to be solved, and students also "feel" a need for finding the solutions.
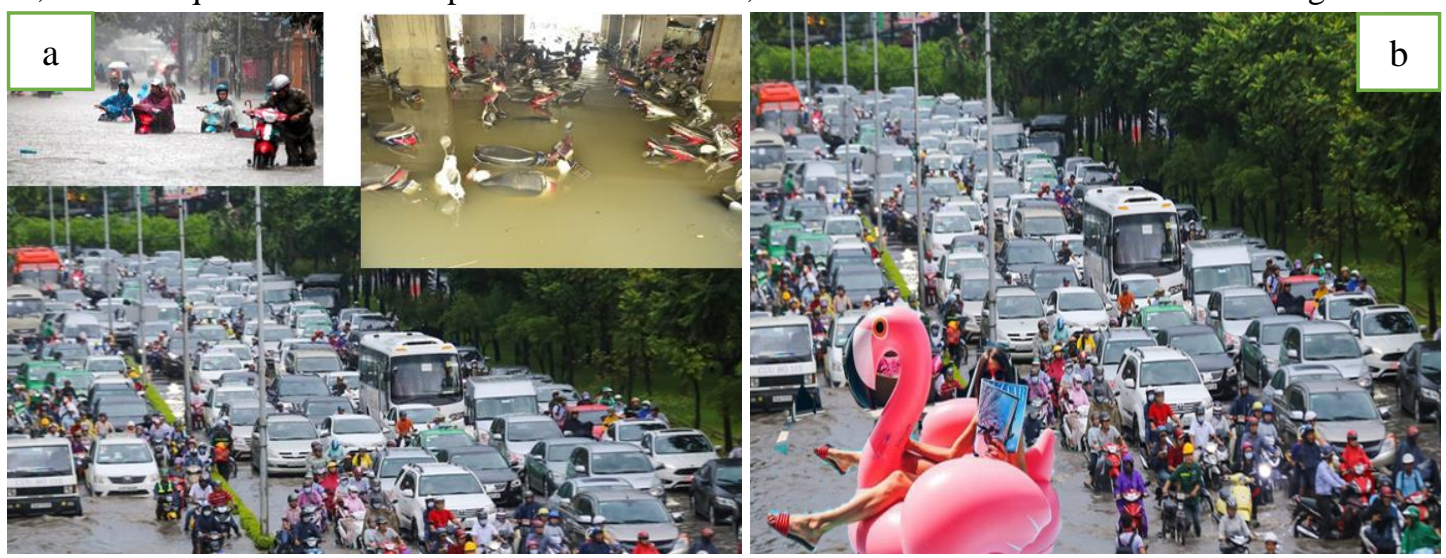

Figure 1. Nuisances are caused by prolonged $(a)$ rain and proposed remedy $(b)$

Proposing ways to overcome the above annoyances such as avoiding beams in water for many hours, the vehicle can move like a boat, easily moving the vehicle in case of stall. Groups of students come up with a solution (Figure 1b). Based on the proposed solutions, students conduct analysis, evaluation, and assessment of strengths and weaknesses of each solution. Finally, they choose designing solutions as self-floating cars and motorcycles. 3.3.2. Noise pollution background in Binh Duong - an industrial province

When content of knowledge-oriented to learn about sounds, sound sources, soundproofing materials, we use the context of Binh Duong, an industrial province. This is a place of centralizing many residential manufactories and companies (Figure 2). The noise pollution problem is quite serious. Students have had experience this situation more or less. Therefore, we build the theme of designing noise-proof houses to limit the impact of noise pollution.

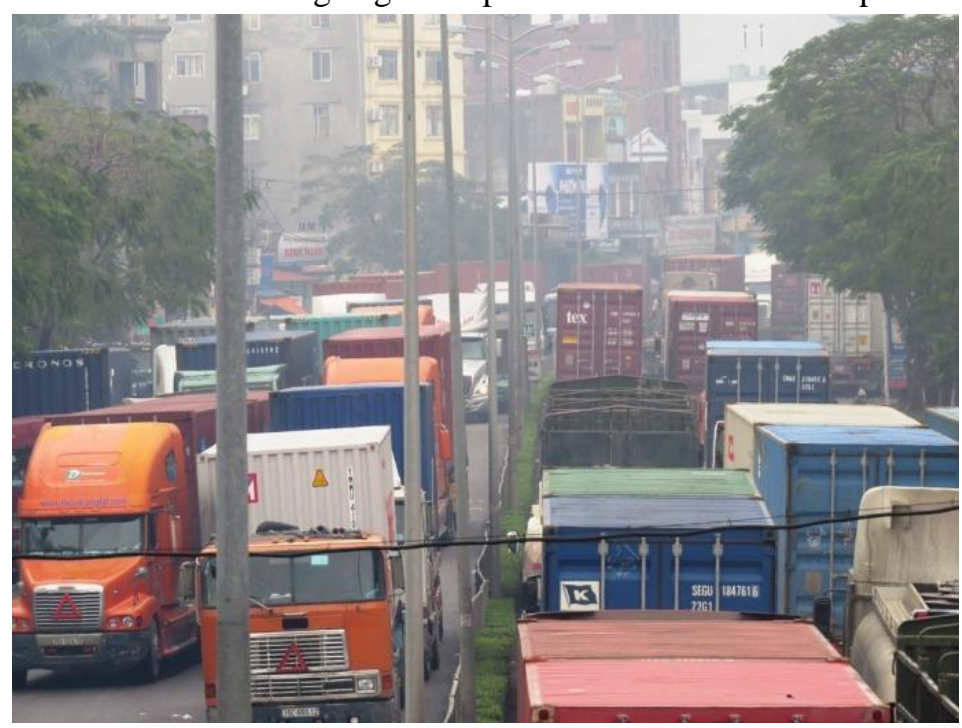

Figure 2. Noise pollution in Binh Duong

\subsubsection{Hot summer day background}

Vietnam is a tropical country. The South shows even more clearly. Ice cream is a great beverage in the summer for students. What is better than when students can make their ice cream in class (Figure 3). In the heat lesson, we built the topic of making ice cream in the classroom within 5 minutes.

\subsection{Research results}

The model was tested at Block 8 of Thoi Hoa secondary school, Tan Phuoc Khanh High School, Phu Giao Secondary School at Binh Duong province performed at the STEM / STEAM experience festival held by Binh Duong province. 
The experiment was conducted in the mainstream class and the STEM / STEAM experience festival; pupils work on a product (Figure 3) and make a presentation (Figure 4).
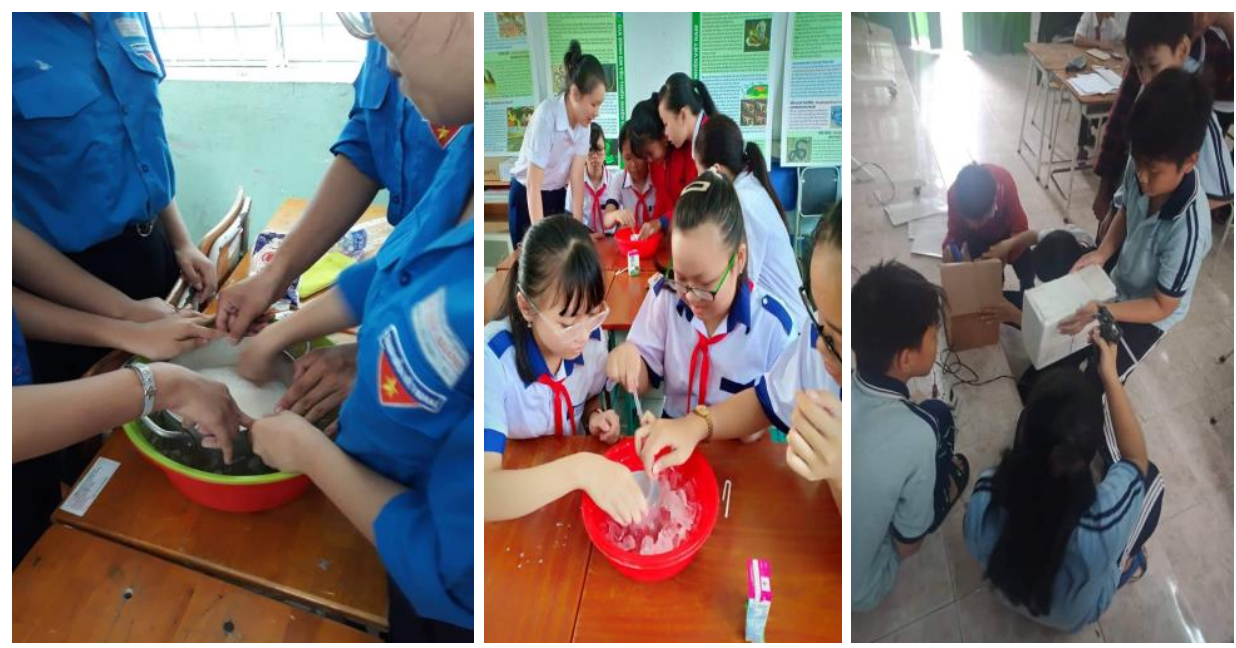

Figure 3. Pupils work on products

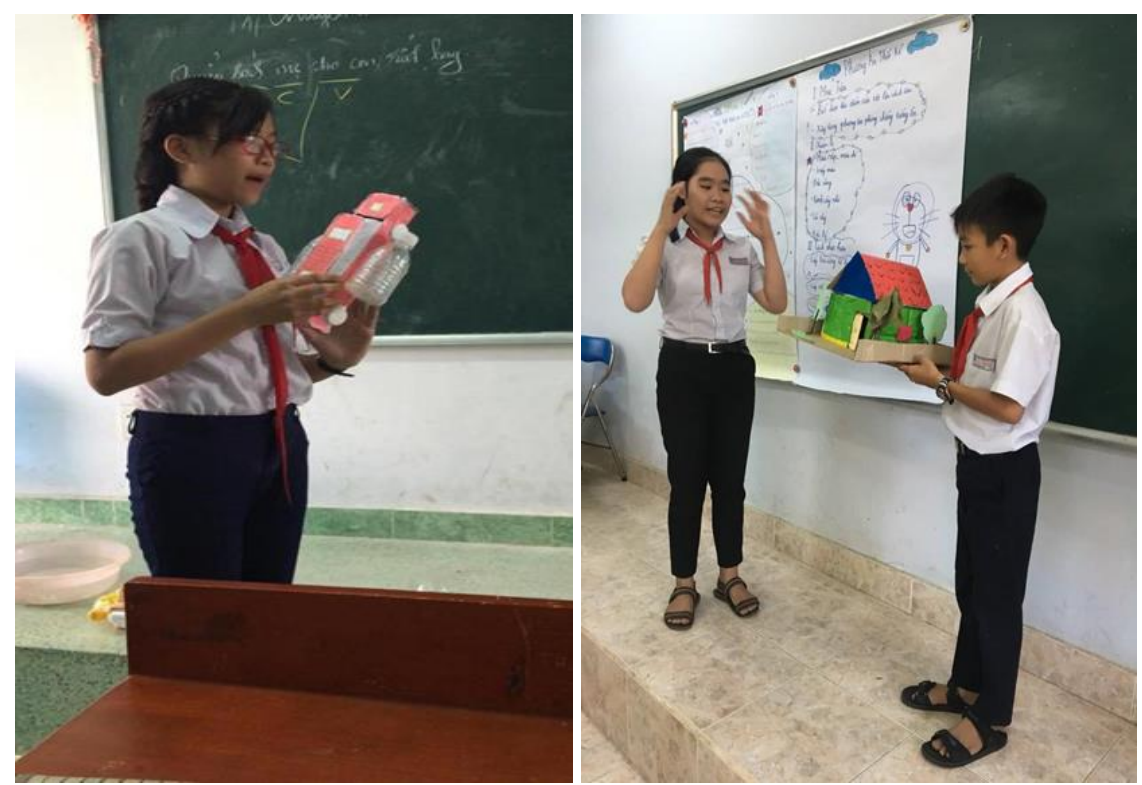

Figure 4. Pupils report the results

Results of the survey on students' interest showed that over $90 \%$ of students actively participate in this method of learning. These are seen as good signals about creating an atmosphere and motivating students.

The transfer of tasks is well received by students because the context is attached to reality. The hint questions have been linked with easy students' understanding because students have been more or less experienced and witnessed.

In the problem of finding solutions, students have a lot of practical experience, so the proposal of ideas is more "real".

Survey on the level of lesson knowledge based on an objective multiple-choice knowledge test (using common knowledge tests that traditional lessons still conduct), then teaching according to the STEM model students had achieved pretty good results accounted for over $80 \%$, higher than the control class with $66 \%$. Thus, this model still ensures that students achieve the same knowledge goals as traditional classrooms, even better, and through which they can develop skills: science, technology, engineering, mathematics, critical thinking, project-based work, presentations... 


\section{DISCUSSION AND CONCLUSION}

Thus, the STEM model in teaching hours applying knowledge of Physics associated with the real context brings positive results. Students do not feel surprised or shocked when changing to a new way of learning. On the contrary, students feel excited and close to their lives. This means that science has come to life. By the way of designing STEM lessons above, we recommend not only in hours applying Physics knowledge as well as other sciences but also apply in opening lessons and a context associated with local reality should be chosen.

\section{REFERENCES}

British Council (2017). Impressive aspects of STEM approach application in Vietnam. Accessed from https://www.britishcouncil.vn/en/programmes/education/science-innovation/success-stories/impressive-aspectsstem-approach-application-vietnam

Do Duc Thai (2017). What could Vietnam learn from STEM?. Accessed from https://dantri.com.vn/giao-duckhuyen-hoc/viet-nam-hoc-duoc-gi-tu-giao-duc-stem-20170727085028452.htm

Le Xuan Quang (2017). Teaching STEM-oriented general technology. Doctor of Education Science Thesis, Hanoi University of Education.

Ministry of Education and Training (2019a). Developing and implementing STEM education topics in high schools. Training materials (for 15 pilot provinces).

Ministry of Education and Training (2019b). General school education program in new general education program.

Nguyen Chi Thanh, Dang Van Son (2019). STEM education in Vietnam: tools and methods. Accessed from http://hdll.vn/en/thong-tin-ly-luan/giao-duc-stem-tai-viet-nam-cong-cu-va-phuong-thuc.html

Nguyen Thanh Hai (2019). STEM / STEAM education from hands-on experience to creative thinking. Young Publishing House.

Nguyen Thanh Nga (Editor), Phung Viet Hai, Nguyen Quang Linh, Hoang Phuoc Muoi (2017). Design and organize the theme of STEM education for middle and high school students. University Pedagogy Ho Chi Minh City.

Nguyen Van Bien (2015). Natural science integrated topic development process. Journal of Science, Hanoi University of Education, 2(60), 61-66.

Tsupros, N., Kohler, R. \& Hallinen, J. (2009). STEM education: a project to identify the missing components. Intermediate Unit 1 and Carnegie Mellon, Pennsylvania. 